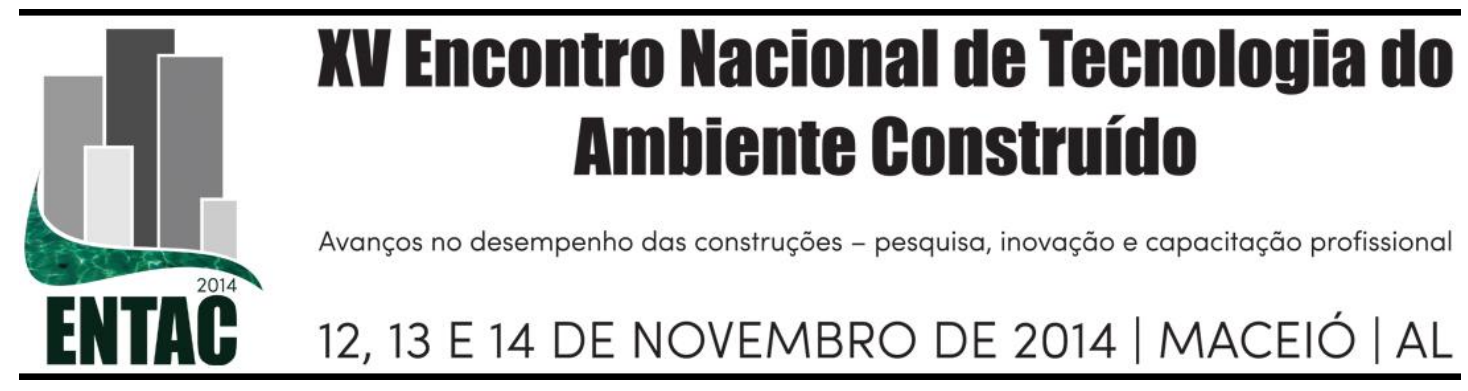

\title{
AVALIAÇÃO DO DESEMPENHO DE ARGAMASSA REFORÇADA COM TELA METÁLICA ATRAVÉS DO ENSAIO DE TRAÇÃO NA FLEXÃO
}

\author{
ANTUNES, Giselle Reis (1); MASUERO, Angela Borges (2); MAÇANEIRO, \\ Mikael Nathan (3) \\ (1) NORIE/UFRGS, (51) 3308-3518, e-mail: engcivil.giselle@gmail.com (2)
} NORIE/UFRGS, e-mail: angela.masuero@ufrgs.br, (3) NORIE/UFRGS, e-mail: mikaelnathan@hotmail.com

\section{RESUMO}

No Brasil, muito corriqueiramente telas metálicas são recomendadas em revestimentos de fachadas com função de incrementar a resistência à tração da argamassa, evitar a formação de fissuras perceptíveis a olho nu e garantir o desempenho do sistema. E, embora haja normas como a NBR 7200 (ABNT, 1998) e a NBR 13755 (ABNT, 1996) que estimulem e/ou indiquem o uso da argamassa armada nos revestimentos e exijam que a resistência por parte da tela aos esforços deva ser comprovada, não é explicitado o tipo de ensaio a ser utilizado para esta comprovação. Neste sentido, este trabalho surge no sentido de propor o uso do ensaio de tração na flexão para avaliar o desempenho de argamassas armadas, reforçadas com tela metálica. Para tanto, foram moldadas 20 amostras de tela metálica eletrosoldada galvanizada $(15 \times 30) \mathrm{cm}$, de malha quadrada (25x25) $\mathrm{mm}$ de diâmetro de fio de $1,24 \mathrm{~mm}$, inseridas na metade da espessura da camada de uma argamassa industrializada de $5 \mathrm{~cm}$. Depois de endurecidos, submeteram-se os corpos de prova a um ensaio de tração na flexão de 4 pontos, até a ruptura da argamassa. A partir dos resultados obtidos considerou-se o ensaio proposto apto para caracterização do desempenho de argamassas armadas diante da sua facilidade de execução, número necessário de corpos de prova a ser ensaiado bastante pequeno, e devido a sua reduzida variabilidade.

Palavras-chave: Desempenho de argamassa armada, Reforço com tela metálica, Ensaio de tração na flexão.

\begin{abstract}
In Brazil, metallic screens are very routinely recommended for facade coatings with function to increase the tensile strength of the mortar, prevent the formation of cracks visible to the naked eye and guarantee the system performance. And while there are standards such as NBR 7200 (ABNT, 1998) and NBR 13755 (ABNT, 1996) to encourage and/or require the use of mortar in coatings and require that the resistance to the efforts of the screen must be proved; the type of test to be used for this verification is not
\end{abstract}


explained. In this sense, this work proposes the use of the bending tensile test to evaluate the performance of reinforced mortar, with metallic screens. For this purpose, 20 samples of galvanized metal screen electrowelded (15x30) $\mathrm{cm}$ were molded, square mesh (25x25) $\mathrm{mm}$ wire diameter of $1,24 \mathrm{~mm}$, embedded at half the thickness of the mortar layer industrialized of $5 \mathrm{~cm}$. After hardened were submitted the specimens to a bending tensile test in the 4 points until rupture of the mortar. From the results obtained it was considered appropriated for the proposed performance characterization of reinforced mortars, due to its ease of execution, to required number of specimens to be tested rather small, and due to its reduced variability.

Keywords: Performance of wire mesh, Reinforcement of mortar, Flexural tensile strength test.

\section{INTRODUÇÃO}

\subsection{Contexto e Justificativa}

A perda da estabilidade de revestimentos de argamassa aplicados sobre fachadas é um indício preocupante da carência técnica nesta área da tecnologia construtiva. Lamentavelmente é um fenômeno cada vez mais recorrente em edificações jovens e multipavimentares.

No cenário atual onde a preocupação com o usuário torna-se a cada dia mais relevante e um fator decisivo durante a especificação de materiais e escolha de técnicas construtivas, prevenir a incidência de danos sobre os revestimentos externos é imprescindível.

O sistema de revestimento externo exerce um papel importante no desempenho da edificação, já que possui a função de absorver tensões e aliviar deformações decorrentes das solicitações. Em havendo incompatibilidade entre as condições de deformação da base e a capacidade de acomodar deformações do revestimento de argamassa, podem desencadear-se desde pequenas fissuras no revestimento até o colapso total do mesmo, gerando elevados custos, descrédito para as construtoras e principalmente, desconforto ao usuário.

A nova realidade da construção civil no Brasil é apoiada em normas que exigem desempenho dos materiais, componentes e sistemas construtivos inteiramente centrados no usuário, bem como na qualidade desses. Segundo, por exemplo, a norma de qualidade NBR ISO 9004-4 (ABNT, 2010), em nota:

[...] Melhorias da qualidade são obtidas pela tomada de ações preventivas ou corretivas no processo, de forma a produzir saídas mais satisfatórias e/ou reduzir a frequência de saídas não satisfatórias. Confiar inicialmente na correção das saídas de processos, tais como reparo, retrabalho ou seleção, perpetua as perdas da qualidade.

Para garantir o desempenho da edificação e proporcionar aos usuários confiabilidade e conforto, tem-se a integração de todos os elementos constituintes da edificação, não somente o comportamento individual destes.

Sabe-se que um revestimento em argamassa armada une as características frágeis da argamassa com as características dúcteis que a tela metálica traz consigo. Ao contrário do aço, os materiais frágeis, como a argamassa, não deformam plasticamente, pelo contrário, o alívio de tensões ao superar o limite de resistência à tração acarreta na fratura dos mesmos (VanVlack, 1970), deste modo adotar soluções no sentindo 
incrementar essa resistência é extremamente relevante, e neste ponto que a tela age, agregando resistência à tração ao mesmo, de modo a garantir o desempenho do sistema.

A argamassa reforçada com tela metálica é bastante difundida na indústria na construção civil, e é apoiada pela NBR 7200 (ABNT, 1998) a qual indica o uso de tela metálica, plástica ou de outro material semelhante na junção da base sempre que ela for composta por diferentes materiais e for submetida a esforços que gerem deformações diferenciais (tais como balanços, platibandas e últimos pavimentos). A NBR 13755 (ABNT, 1996) também indica o uso de tela metálica soldada, no entanto restringe a uma constituída de fio com diâmetro igual ou superior a $2 \mathrm{~mm}$ e malha com abertura quadrada de $5 \times 5 \mathrm{~cm}$, inserida na camada de argamassa de regularização ou no emboço, e ancorada na estrutura-suporte; sempre que a espessura necessária, a partir do chapisco até o tardoz da placa cerâmica, for superior a $25 \mathrm{~mm}$, cuja função é inibir a retração. Ainda assim, o uso deste material é incipiente no que tange a caracterização de propriedades do mesmo.

A proposta de ensaio à tração na flexão apresentada nesta pesquisa faz parte de uma pesquisa maior de doutorado, em andamento, que trata de revestimentos reforçados com tela metálica. E a etapa em questão através do teste sugerido, tem o propósito de contribuir para avaliação do requisito de desempenho de revestimentos em argamassa armada. $\mathrm{O}$ ensaio soma-se ao grupo de métodos de ensaio existentes para cumprimento das exigências apresentadas no item 7.2, da NBR 15575-4 (ABNT, 2013) que aborda sistemas de vedações verticais internas e externas, no sentido de prevenir o surgimento de deslocamentos, fissuras e falhas.

\section{PROCEDIMENTOS METODOLÓGICOS}

\subsection{Descrição do ensaio}

Inicialmente, de modo a caracterizar o comportamento da argamassa industrializada utilizada nesta pesquisa, indicada pelo fabricante para revestimento externo, realizaramse diferentes ensaios considerando os principais parâmetros sugeridos pelas normas brasileiras.

De modo avaliar o desempenho revestimentos de argamassa reforçados com tela metálica, o ensaio proposto nesta pesquisa representa um dos principais esforços impostos em fachadas, trata-se de tensão de tração na flexão. Para tanto, previu-se um ensaio de tração em 4 pontos, inspirado no adotado para caracterização de concreto, descrito na NBR 12142 (ABNT, 2010) inclusive com uso do mesmo dispositivo de flexão descrito na norma citada, capaz de assegurar a aplicação da força perpendicularmente às faces superior e inferior do corpo de prova, sem excentricidades.

Com se trata de um ensaio embora adaptado, inovador para argamassa armada, moldaram-se 20 corpos de prova, que segundo a literatura voltada às aplicações das metodologias quantitativas em estatística, é uma amostra representativa da população, embora esse número varie de autor para autor, o que equivale aproximadamente $10 \% \mathrm{a}$ $20 \%$ da população, abaixo do qual uma amostra é considerada pequena. Portanto cortaram-se 20 amostras de tela metálica eletrosoldada galvanizada $(15 \times 30) \mathrm{cm}$, de malha quadrada $(25 \times 25) \mathrm{mm}$ de diâmetro de fio de $1,24 \mathrm{~mm}$, as quais foram inseridas na metade da espessura da camada de uma argamassa industrializada de $5 \mathrm{~cm}$ e moldadas numa fôrma especialmente desenvolvida para este tipo de ensaio, conforme a figura 1 . 
Figura 1 - Esquema da fôrma usada para moldagem do corpo de prova de argamassa reforçado com tala para ensaio de tração na flexão.
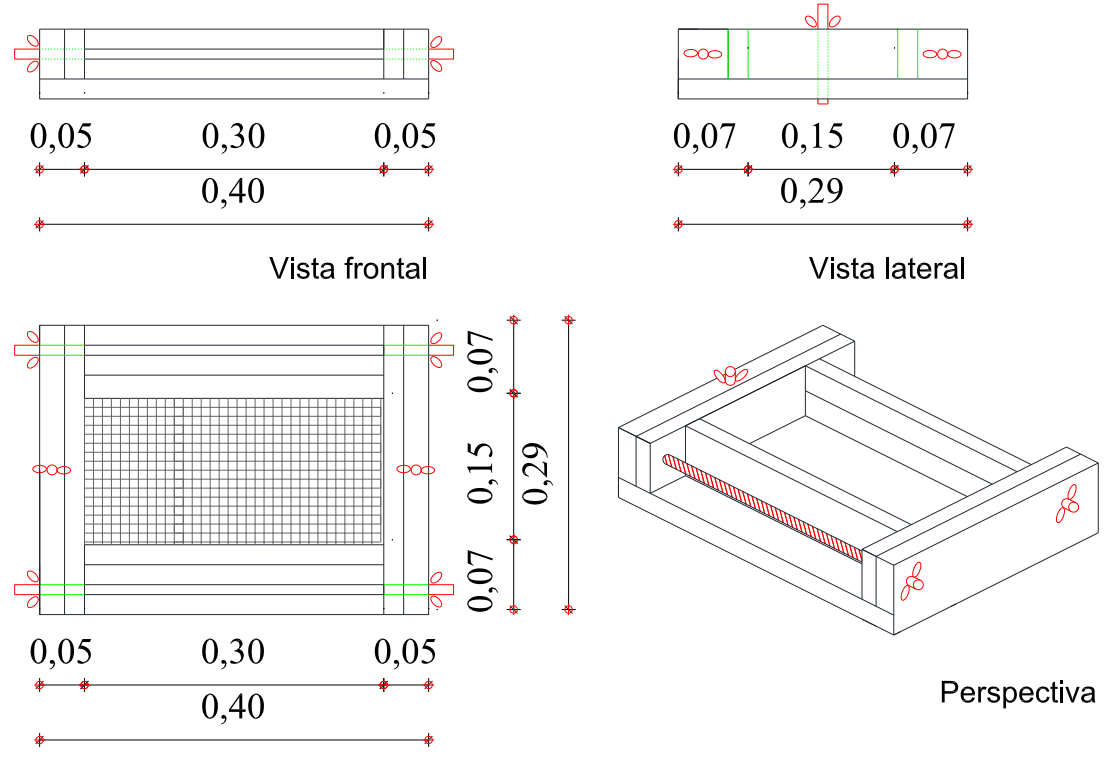

Perspectiva

Planta baixa

A tipologia de tela metálica adotada nesta pesquisa, malha $(25 \times 25) \mathrm{mm}$ de diâmetro de fio de 1,24 $\mathrm{mm}$ e espessura de fio, diferente da mencionada na NBR 13755 (ABNT, 1996), visto que optou-se pela adoção do usual no mercado da construção civil com fins de reforço de revestimentos argamassados.

Inicialmente, procedeu-se com a caracterização dos materiais adotados no ensaio: a tela metálica de um único fabricante e a argamassa industrializada.

Figura 2 - Ensaios de caracterização da argamassa, a) ultrassom para obtenção do módulo de elasticidade, b) tomada de medidas para cálculo da densidade de massa no estado endurecido, c) ensaio de tração na flexão e d) de compressão.
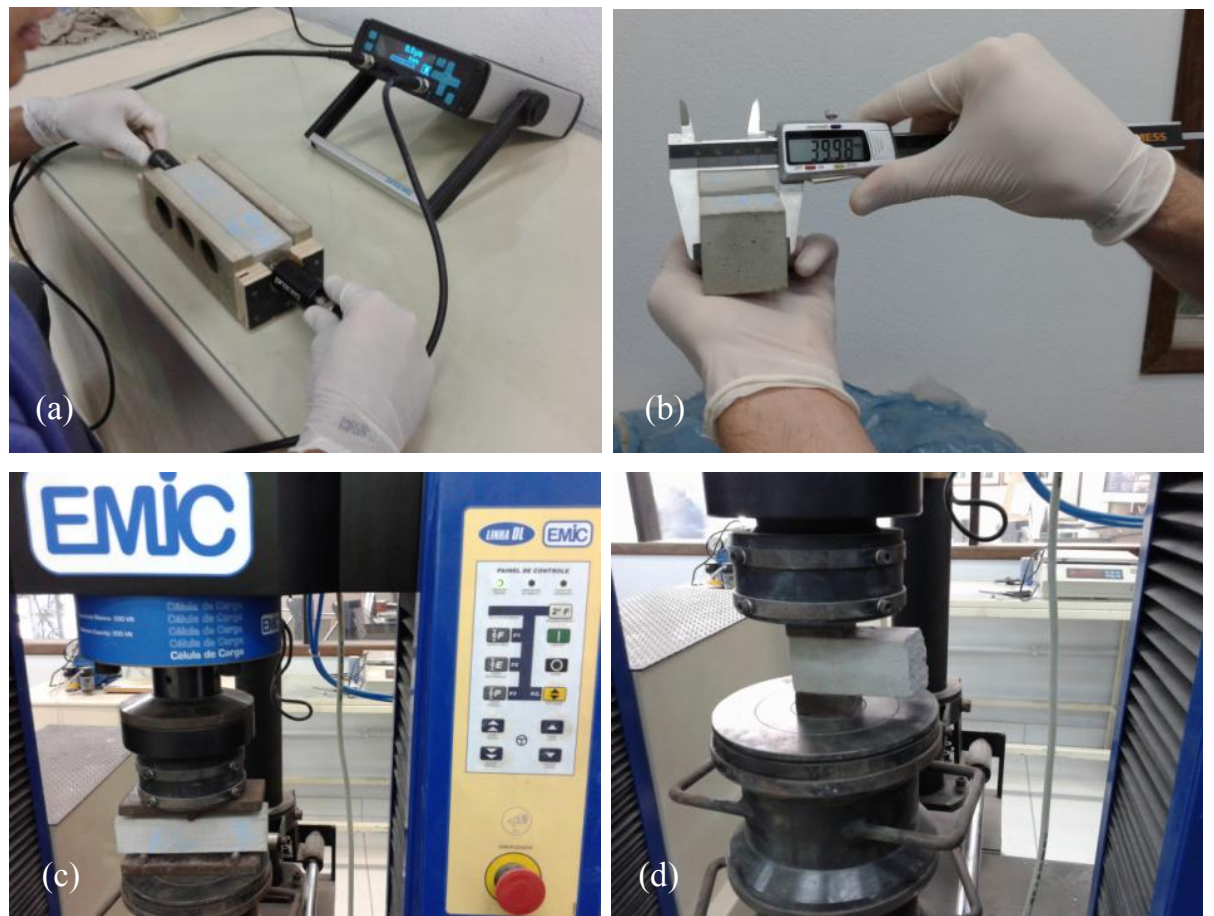
Em seguida procedeu-se com a moldagem da argamassa armada. Primeiro a argamassa industrializada é depositada na fôrma numa camada de $2,5 \mathrm{~cm}$ logo após a tela é imersa, então se efetuam 8 batidas leves com martelo de borracha, em cada um dos quatro lados da forma; posteriormente engaveta-se a tela metálica sobre a camada inicial procedendo-se com o aperto da mesma sobre argamassa; os $2,5 \mathrm{~cm}$ restantes de altura da fôrma são preenchidos com argamassa e novamente efetua-se mais 8 golpes em cada uma das quatro faces da forma a fim de promover o adensamento da argamassa e retirar possíveis bolhas (figura 3). Sobre a forma se passa uma régua metálica, a fim de regularizar a superfície do corpo de prova.

Após moldados todos os corpos de prova, de caracterização das argamassas e do ensaio de ruptura da argamassa armada, foram cobertos com sacos plásticos permanecendo em ambiente durante 24 horas e posteriormente desformados. Depois da desforma os corpos de prova de caracterização da argamassa reforçada com tela metálica foram dispostos em câmara climatizada, com temperatura e umidade relativa do ar, controladas, de $23 \pm 2^{\circ} \mathrm{C}$ e $60 \pm 5 \%$, respectivamente.

\section{Figura 3 - Moldagem dos corpos de prova para o ensaio de tração na flexão da de argamassa reforçada com tela metálica.}

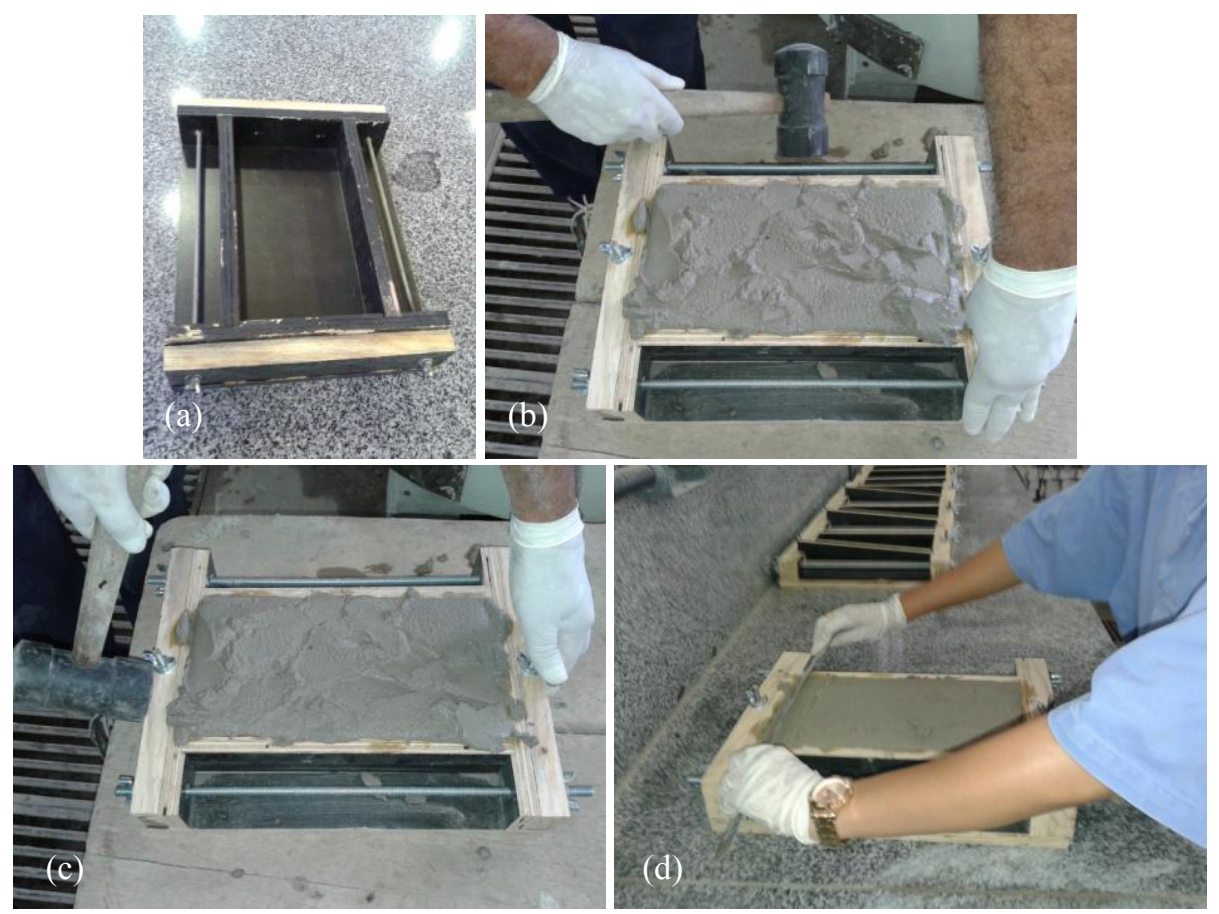

De modo a avaliar a capacidade do sistema de argamassa reforçada com tela metálica resistir à ruptura quando submetido ao esforço de tração na flexão, adotou-se a velocidade de carregamento igual a $0,05 \mathrm{KN} / \mathrm{s}$, conforme indicado na NBR 13279 (ABNT, 2005) e, para a realização do mesmo, utilizou-se uma máquina de ensaios da marca EMIC, modelo DL 20000, disponível no Laboratório de Materiais e Tecnologia do Ambiente Construído (LAMTAC), da Universidade Federal do Rio Grande do Sul (UFRGS). $\mathrm{O}$ ensaio, que pode ser observado na figura 4 , foi realizado com temperatura e umidade controlada de $23 \pm 2^{\circ} \mathrm{C}$ e umidade relativa do ar de $60 \pm 5 \%$, ver figura 5 .

Optou-se por realizar o ensaio de tração na flexão em quatro pontos, ou seja, com o corpo de prova biapoiado e com aplicação da carga em dois pontos equidistantes dos 
apoios. Com este tipo de ensaio aplicado com 4 apoios entende-se que os dados obtidos tenho menos ruídos e maior precisão do que com 3 apoios, e permite medir satisfatoriamente a propriedade desejada. O ensaio termina quando é atingida a carga máxima de ruptura suportada pelo material. Para melhor alinhar o corpo de prova diante dos apoios, e garantir que os esforços sejam simétricos e efetivamente aplicados nos pontos corretos, demarcou-se com linhas o mesmo nos posicionamentos devidos, conforme é possível verificar na figura 4.

Figura 4 - Desenho esquemático do ensaio de tração na flexão com 4 apoios.

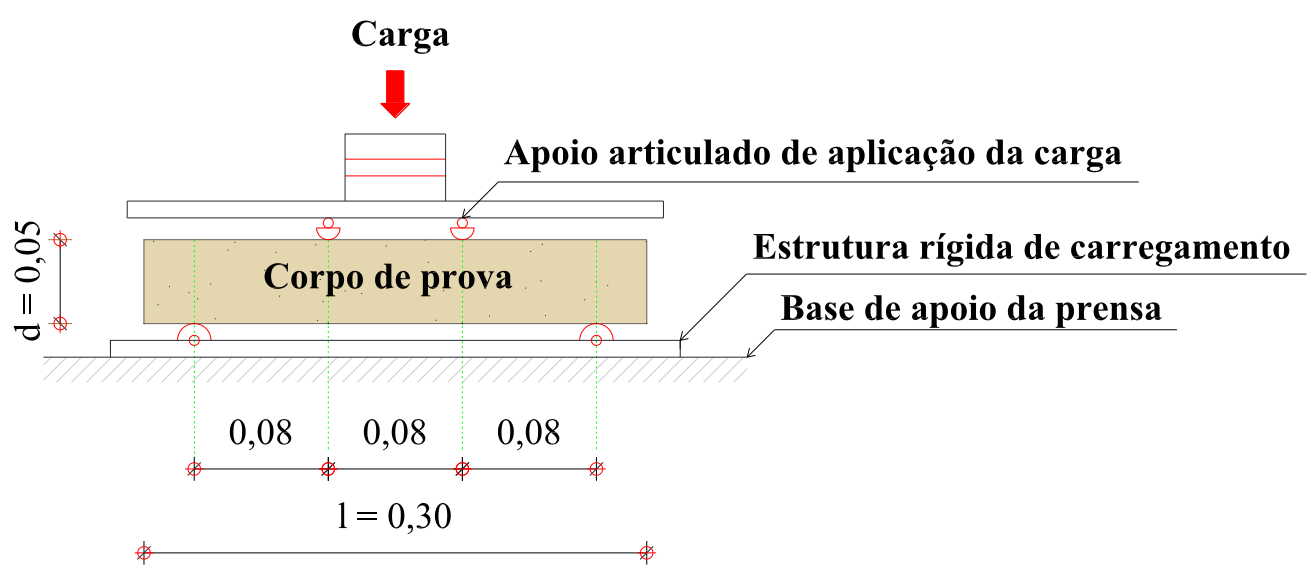

Figura 5 - Execução do ensaio de tração na flexão de argamassa reforçada com tela metálica.
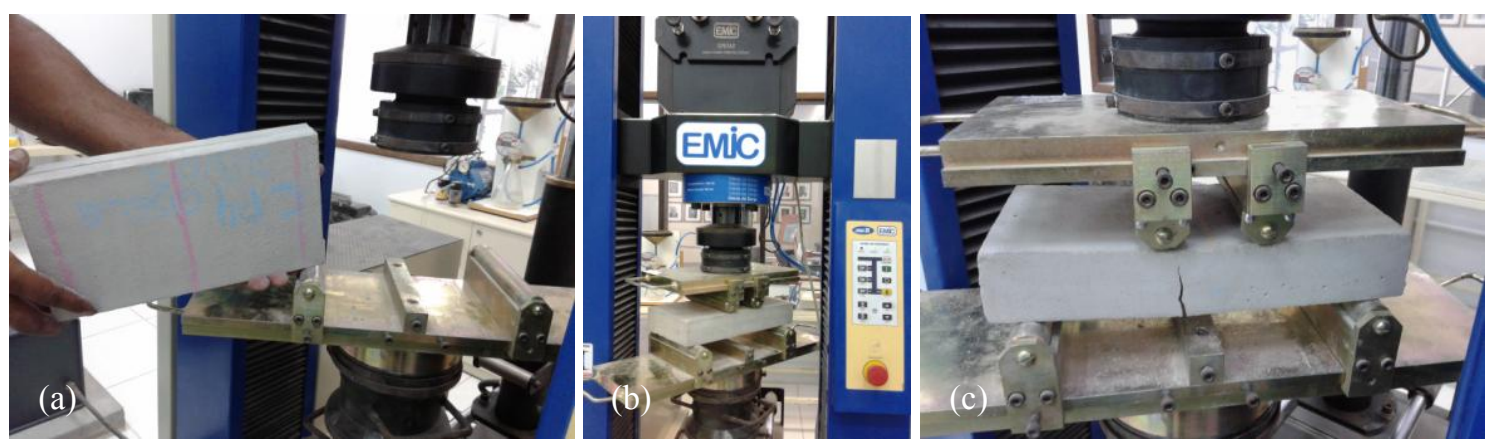

Para melhor avaliação dos resultados obtidos nos ensaios desenvolvidos nesta pesquisa foram utilizados tratamentos estatísticos.

\subsection{Cálculos adotados}

Os resultados obtidos para a resistência à tração na flexão da argamassa armada foram obtidos conforme equação a seguir.

$$
\sigma_{t f}=\frac{P l}{b d^{2}}
$$

onde, $\sigma_{\mathrm{tf}} \quad=$ resistência à tração na flexão, em $\mathrm{MPa}$;

$\mathrm{P} \quad=$ carga máxima aplicada, em $\mathrm{N}$;

$1=$ distância entre cutelos de suporte, em mm;

$\mathrm{b} \quad=$ largura média do corpo de prova na seção de ruptura, em mm;

$\mathrm{d}=$ altura média do corpo de prova, na seção de ruptura, em mm. 
Ao final, no intuito de popularizar o ensaio descrito neste trabalho, verificou-se qual o número mínimo de amostras seria suficiente para adotá-lo em caracterizações futuras da argamassa armada sem comprometimento dos resultados, aplicando-se a seguinte equação, extraída da Estatística:

$$
e=\frac{z \sigma_{x}}{\sqrt{n}}
$$

onde, $\mathrm{e}_{\mathrm{f}} \quad=$ margem de erro máximo que se quer admitir;

$\mathrm{z} \quad=$ desvio do valor médio, para alcançar o nível de confiança desejado;

$\sigma_{\mathrm{x}} \quad=$ desvio padrão da população;

$\mathrm{n} \quad=$ tamanho da amostra.

\section{APRESENTAÇÃO E ANÁLISE DOS RESULTADOS}

Neste item os resultados obtidos, no ensaio de resistência à tração na flexão da argamassa reforçada com tela metálica são apresentados e seguidos das respectivas discussões.

Com o intuito de caracterizar o comportamento da argamassa industrializada utilizada nesta pesquisa, indicada pelo fabricante para revestimento externo, realizaram-se diferentes ensaios considerando os principais parâmetros sugeridos por norma, apresentados na tabela 1 .

Tabela 1 - Caracterização da argamassa industrializada utilizada

\begin{tabular}{|c|c|c|c|c|c|}
\hline Ensaio & Norma & $\begin{array}{c}\text { Resultado } \\
\text { médio }\end{array}$ & $\begin{array}{c}\text { Desvio } \\
\text { padrão }\end{array}$ & $\begin{array}{c}\text { CV } \\
(\%)\end{array}$ & $\begin{array}{c}\text { Classificação } \\
\text { NBR 13281 } \\
\text { (ABNT, 2005) }\end{array}$ \\
\hline Índice de consistência & $\begin{array}{c}\text { NBR 13276 } \\
(\mathrm{ABNT}, 2005)\end{array}$ & $251,70 \mathrm{~mm}$ & 0,65 & 2,58 & \\
\hline $\begin{array}{c}\text { Densidade de massa } \\
\text { no estado endurecido }\end{array}$ & $\begin{array}{c}\text { NBR 13280 } \\
\text { (ABNT, 2005) }\end{array}$ & $2022,67 \mathrm{~kg} / \mathrm{m}^{3}$ & 36,27 & 1,79 & $\mathrm{M} 4$ \\
\hline $\begin{array}{c}\text { Módulo de } \\
\text { elasticidade dinâmico }\end{array}$ & $\begin{array}{c}\text { NBR 15630 } \\
\text { (ABNT, 2009) }\end{array}$ & $11937,22 \mathrm{MPa}$ & 461,55 & 3,87 & \\
\hline $\begin{array}{c}\text { Resistência à } \\
\text { compressão }\end{array}$ & $\begin{array}{c}\text { NBR 13279 } \\
\text { (ABNT, 2005) }\end{array}$ & $5,55 \mathrm{MPa}$ & 0,4 & 7,28 & $\mathrm{P} 4$ \\
\hline $\begin{array}{c}\text { Resistência à tração } \\
\text { na flexão }\end{array}$ & $\begin{array}{c}\text { NBR 13279 } \\
\text { (ABNT, 2005) }\end{array}$ & $2,11 \mathrm{MPa}$ & 0,17 & 8,08 & $\mathrm{R} 3$ \\
\hline
\end{tabular}

Enquanto para a tela metálica, após submetê-la ao ensaio de tração simples conforme Antunes, Silva e Masuero (2013), foram registrados uma carga máxima média de $4,50 \mathrm{KN}$, com desvio padrão de 0,15 , e um coeficiente de $3,44 \%$, valores bem baixos em se tratando de ensaios com materiais metálicos. No caso do limite de resistência, este foi de $452,86 \mathrm{MPa}$, com desvio padrão de $31,18 \mathrm{MPa}$ e com coeficiente de variação de $6,89 \%$, evidenciando um rigoroso controle de qualidade na produção da tela (tabela 2). 
Tabela 2 - Características quanto à tração da tela metálica.

\begin{tabular}{|c|c|c|c|c|}
\hline \multicolumn{5}{|c|}{ Características quanto à tração da tela metálica } \\
\hline Corpo de prova & $\begin{array}{c}\text { Carga máxima } \\
(\mathrm{KN})\end{array}$ & $\begin{array}{c}\text { Limite de resistência } \\
(\mathrm{MPa})\end{array}$ & \multicolumn{2}{|c|}{ Quantidade e locais de ruptura } \\
\hline 1 & 4,6 & 462,92 & \multicolumn{2}{|c|}{4 pontos no fio } \\
\hline 2 & 4,2 & 422,67 & \multicolumn{2}{|c|}{5 pontos no fio } \\
\hline 3 & 4,5 & 452,86 & \multicolumn{2}{|c|}{5 pontos no fio } \\
\hline 4 & 4,6 & 462,92 & \multicolumn{2}{|c|}{4 pontos no fio } \\
\hline 5 & 4,6 & 462,92 & \multicolumn{2}{|c|}{4 pontos no fio } \\
\hline 6 & 4,5 & 452,86 & \multicolumn{2}{|c|}{4 pontos no fio } \\
\hline Média & 4,5 & 452,86 & \multirow{2}{*}{$\begin{array}{c}\text { Rupturas no fio } \\
(\%)\end{array}$} & \multirow{2}{*}{$\begin{array}{c}\text { Rupturas na } \\
\text { solda }(\%)\end{array}$} \\
\hline Desv. Pad.: & 0,15 & 31,18 & & \\
\hline $\mathrm{CV}(\%)$ & 3,44 & 6,89 & 100 & 0 \\
\hline
\end{tabular}

A carga, no ensaio de tração na flexão da argamassa armada, foi aplicada sobre o corpode-prova, continuamente e sem choques, com crescimento constante de velocidade até a ruptura da argamassa, percebida facilmente a olho nu. Em todos os corpos de prova observou-se que a fissura localizou-se entre os apoios inferiores do dispositivo de ensaio. Os resultados obtidos no ensaio são apresentados na tabela 3.

\section{Tabela 3 - Características da argamassa armada quanto à tração na flexão}

\begin{tabular}{|c|c|c|c|}
\hline $\mathbf{C P}$ & $\begin{array}{c}\text { Carga de ruptura } \\
(\mathrm{N})\end{array}$ & \multicolumn{2}{|c|}{$\begin{array}{l}\text { Tensão de tração na flexão } \\
\text { (MPa) }\end{array}$} \\
\hline 1 & 2365,00 & \multicolumn{2}{|c|}{1,51} \\
\hline 2 & 2397,00 & \multicolumn{2}{|l|}{1,53} \\
\hline 3 & 2549,00 & \multicolumn{2}{|l|}{1,63} \\
\hline 4 & 2503,00 & \multicolumn{2}{|l|}{1,60} \\
\hline 5 & 2627,00 & \multicolumn{2}{|l|}{1,68} \\
\hline 6 & 3553,00 & \multicolumn{2}{|l|}{2,27} \\
\hline 7 & 2831,00 & \multicolumn{2}{|l|}{1,81} \\
\hline 8 & 2654,00 & \multicolumn{2}{|l|}{1,70} \\
\hline 9 & 2838,00 & \multicolumn{2}{|l|}{1,82} \\
\hline 10 & 2529,00 & \multicolumn{2}{|l|}{1,62} \\
\hline 11 & 2719,00 & \multicolumn{2}{|l|}{1,74} \\
\hline 12 & 2555,00 & \multicolumn{2}{|l|}{1,64} \\
\hline 13 & 2956,00 & \multicolumn{2}{|l|}{1,89} \\
\hline 14 & 2621,00 & \multicolumn{2}{|l|}{1,68} \\
\hline 15 & 2338,00 & \multicolumn{2}{|l|}{1,50} \\
\hline 16 & 3054,00 & \multicolumn{2}{|l|}{1,95} \\
\hline 17 & 2312,00 & \multicolumn{2}{|l|}{1,48} \\
\hline 18 & 2621,00 & \multicolumn{2}{|l|}{1,68} \\
\hline 19 & 2529,00 & \multicolumn{2}{|l|}{1,62} \\
\hline 20 & 2187,00 & \multicolumn{2}{|l|}{1,40} \\
\hline P média $(\mathrm{N})$ : & 2624,57 & otf média (MPa): & 1,68 \\
\hline Desv. Pad.: & 245,99 & Desv. Pad.: & 0,31 \\
\hline CV (\%): & 9,37 & CV (\%): & 18,74 \\
\hline
\end{tabular}


Através da observação dos principais parâmetros referentes à caracterização da argamassa reforçada com tela metálica, apresentados anteriormente na tabela 3 , registrou-se uma carga máxima de ruptura média de $2624,57 \mathrm{~N}$, desvio padrão de $245,99 \mathrm{~N}$ e um coeficiente de variação igual a 9,37\%. Quanto à resistência à tração na flexão atingida, esta foi de $1,68 \mathrm{MPa}$, com desvio padrão de $0,31 \mathrm{MPa}$ e um coeficiente de variação de 18,74\%, demonstrando uma reduzida variabilidade do ensaio, com precisão suficiente para adotá-lo na avaliações de desempenho deste tipo de sistema de revestimento, como esperado.

De modo a incentivar sua reprodutibilidade em ensaios futuros aplicou-se a equação 2 , considerando que os resultados experimentais obtidos no ensaio, se enquadram em uma distribuição normalizada, definiu-se uma margem de erro (intervalo no qual se espera encontrar o dado que se deseja medir do universo) entre $-1,96$ e $+1,96$ da média, de modo a englobar os valores que cobrem 95\% dos casos, e adotando-se como erro máximo a ser tolerado um valor igual a $2,5 \%$ da resistência média à tração na flexão. Com isto, obteve-se uma estimativa do tamanho mínimo da amostra de fato necessário para futuros ensaios que avaliem este parâmetro de desempenho da argamassa armada, definido em 4 amostras, resultado incentivador visto que se trata de um número reduzido e de fácil execução.

\section{CONSIDERAÇÕES FINAIS}

A partir das análises efetuadas nesta pesquisa, considera-se o ensaio proposto apto para a caracterização de telas metálicas com malha quadrada, no que se refere ao ensaio de tração na flexão, considerando sua facilidade de execução, número necessário de corpos de prova e ser ensaiado bastante pequeno, e devido à reduzida variabilidade.

Deste modo, a presente pesquisa apresentou importantes contribuições e representa um grande salto no que tange a avaliação de desempenho de revestimentos de argamassa reforçados com tela metálica, até então bastante escasso, nacionalmente.

Com o intuito de prosseguir com a avaliação do ensaio a tração na flexão apresentado neste artigo estão sendo realizados novos testes da configuração de corpo de prova proposta com e sem o uso de tela metálica, para realizar novas comparações.

\section{AGRADECIMENTOS}

Os autores expressam seus agradecimentos ao Conselho Nacional de Desenvolvimento Científico e Tecnológico - CNPq e à Coordenação de Aperfeiçoamento de Pessoal de Nível Superior - CAPES, pelo suporte financeiro. Ao Laboratório de Materiais e Tecnologia do Ambiente Construído - LAMTAC pela disponibilização de equipamentos, apoio dos servidores e ao Núcleo Orientado para a Inovação da Edificação - NORIE por apoiar estudos e pesquisas desenvolvidas pelo grupo de tecnologia de materiais e sistemas construtivos.

\section{REFERÊNCIAS}

ANTUNES, G. R.; SILVA, K. K. da.; MASUERO, A.B.. Estudo comparativo de resistência à tração em telas metálicas adotadas no reforço de argamassa, $55^{\circ}$ Congresso Brasileiro do

Concreto. Gramado, IBRACON, CBC, 2013. 
ASSOCIAÇÃO BRASILEIRA DE NORMAS TÉCNICAS (ABNT). NBR 7200: Execução de revestimento de paredes e tetos de argamassas inorgânicas - Procedimento. Rio de Janeiro, 1998.

NBR 12142: Concreto - Determinação da resistência à tração na flexão de corpos de prova prismáticos. Rio de Janeiro, 2010.

NBR 13279: Argamassa para assentamento e revestimento de paredes e tetos Determinação da resistência à tração na flexão e à compressão. Rio de Janeiro, 2005.

NBR 13755: Revestimento de paredes externas e fachadas com placas cerâmicas e com utilização de argamassa colante - Procedimento. Rio de Janeiro, 1996.

. NBR 15575-4: Edificações habitacionais - Desempenho Parte 4: Requisitos para os sistemas de vedações verticais internas e externas - SVVIE. Rio de Janeiro, 2013.

NBR ISSO 9004-4: Gestão da qualidade e elementos do sistema de qualidade. Rio de Janeiro, 2010.

VAN VLACK, L. H. Fases cerâmicas e suas propriedades. Princípios de Ciência dos

Materiais. São Paulo. Ed. Edgar Blücher, 1970. P. 199-228. 